\title{
INFLUENCE OF PILE GROUP DENSITY ON MINIMIZING LOCAL SCOUR OF A DOUBLE SPUR DIKE GROUP
}

\author{
Sayed Hashmat SADAT ${ }^{1}$, Akihiro TOMINAGA ${ }^{2}$ \\ ${ }^{1}$ Member of JSCE, Graduate Student of Civil and Environmental Engineering, Nagoya Institute of Technology \\ (Gokiso-cho, Showa-ku, Nagoya 466-8555, Japan) \\ ${ }^{2}$ Member of JSCE, Dr. of Eng., Professor, Dept. of Civil and Environmental Engineering, Nagoya Institute of \\ Technology (Gokiso-cho, Showa-ku, Nagoya 466-8555, Japan)
}

\begin{abstract}
The present study is about flow structure and bed deformation around a group of double spur dike with the main purpose of how to reduce the local scour in the neighborhood of a conventional-type spur dike. Four types of submerged pile group, with different densities were installed in the same area at the upstream adjacent of the first spur-dike. The corresponding effects of each new model on flow and bed deformation mechanism were compared with those of the conventional spur-dike group. Flow velocity was reduced at the neighborhood of the first spur dike in the cases with a pile group. Local scour was also reduced both in depth and volume. With a decrease of the pile density flow patterns became more similar to the conventional case, local scour depth and bed erosion in the spur-dike field were increased. The promotion of sediment deposition in the spur-dike field was observed in the cases with medium and lower pile density, respectively.
\end{abstract}

Key Words: Spur dike, pile group, flow structure, movable bed, local scour

\section{INTRODUCTION}

In recent years, spur dikes with appropriate configurations and combinations become one of the most important hydraulic structures for river restoration and maintenance. For example, the middle Rio Grande has been the focus of a variety of restoration techniques, including the attempts to control bank erosion rates, channel migration rates, and habitat degradation, as shown by Darrow $2004^{1)}$. Also spur dike has been used to protect other structures along the bank from erosion in a river, i.e. the bridge abutments, irrigation intakes etc. In general, a spur dike can be defined as an elongated structure having one end on the bank of a stream and the other end projecting into the current against the flow to train the flow in the desired direction.

Spur dikes are usually organized in sequences to increase the efficiency and enlarge the river reach improved in terms of morphology and eco-systems, because a single spur dike in a river has local effects and brings only a few improvements to a limited extend downstream, as stated in Zhang $2005^{2)}$. Slow velocity zones between the dikes are areas of sediment deposition and can encourage vegetation growth, providing further stabilization of the banks as well as habitat for fish and other aquatic species, Kuhnle et al. 2002 ${ }^{3)}$, Biron et al. 2005 ${ }^{4}$, Tominaga and Matsumoto $2006^{5)}$, and Haltigin et al. $2007^{6}$. Tominaga and Matsumoto 2006 ${ }^{5}$ investigated the diverse riverbed figuration by using skew spur-dike group under submerged flow condition. An alternative arrangement of spur dikes inclined towards upstream was able to create pool-riffle morphology. Local scour as reported in many literatures (Garde et al. 1961 $1^{7)}$, Gill 1972 ${ }^{8)}$, and Tominaga and Matsumoto $\left.2006^{5}\right)$, undermines the durability and performance of spur dike structure as any other hydraulic structure. Two common countermeasures are often practicing to prevent or reduce severe local scour: one is physical one, such as permeability, and the other is geometrical one, such as nosing shape etc. Spur dike could be constructed as a permeable or impermeable structure depending on the type of construction material, as stated by Klaasen et al. $2002^{9)}$. There is a large 
difference of flow patterns and scouring between these two types of spur dike, due to the passage of flow through the permeable structures and reduction of flow velocity near the river bank, as shown by Mioduszewski et al. $2003^{10)}$. The advantages of permeable spur dike over impermeable one in terms of the flow and morphology around spur dike are often demonstrated in literatures (Zhang 2005'), Zhang and Nakagawa 2008 ${ }^{11)}$, and Baba et al. $2010^{12)}$ ). However, some concerns regarding the maintenance and safety of spur dike, river restoration and ecological aspects also rise with the fully permeable structures. In this regard, valuable advances in the performance of spur dikes composed of permeable and impermeable parts have been achieved as presented in Allauddin et al. 2011 ${ }^{13)}$, and Sadat et al. 2013 ${ }^{14)}$.

Flow structure, sediment erosion, maximum local scouring, deposition, geometry and quantity of these features are the dominant design parameters for river engineers and practitioners.

Applying a riprap, revetment, concrete armor, gabion mattress, etc. are common measures of controlling scour around a hydraulic structure, but using a pile group with an optimum arrangement and density will improve the flow and sediment exchange, besides mitigation of scour, in the spur dike field. In this study, several densities of pile group at the adjacent upstream of the first spur dike in a group were considered. The influence of these pile groups on the above mentioned parameters and the resulted advantages of these features were compared with those of the conventional double spur-dike group.

\section{EXPERIMENTAL METHODS}

Five different physical-models are considered here, the first one is the conventional type spur-dike group, and each one of the remaining four models consists of a submerged pile-group combined with a spur-dike group. Fig. 1 shows the plan view of experimental flume and physical models.

A spacing ratio of $S / L_{s}=4$ for the two successive spur dikes was selected based on recommendations given in some literatures. Where $S$ is the streamwise distance from center to center and $L_{s}$ is the length of spur dikes. Each spur dike is $10 \mathrm{~cm}$ in length, $4 \mathrm{~cm}$ in width, and $4.5 \mathrm{~cm}$ height from the initial bed in all cases. Metal cylinders 5 $\mathrm{mm}$ in diameter were used in the experiments to form the pile groups. The piles were placed side by side with different densities inside a square of $10 \mathrm{~cm}$ sides on the bed, with a uniform spacing in both streamwise and cross-streamwise directions and 2.5 $\mathrm{cm}$ height from the initial bed.

The models were placed $6.2 \mathrm{~m}$ downstream from the flow inlet along the one side of a $13 \mathrm{~m}$ long, 0.6 $\mathrm{m}$ wide rectangular flume. In the middle of the flume $4.5 \mathrm{~m}$ from the inlet, uniform sediment recess $6 \mathrm{~m}$ long in $11 \mathrm{~cm}$ thickness was evenly distributed (Fig. 1). The sand was roughly uniform, $d_{50}=0.586$ $\mathrm{mm}$ and specific gravity $=2.55$. Before each experiment the sand bed was leveled and slope of the flume remained constant at 0.0005 through all the cases. To prevent bed deformation immediately after flowing of the shallow high velocity water, the flume was always first gently filled up by water to the desired flow level then the pump was started from a low discharge and gradually reached the designed value $\left(7.7 \times 10^{-3} \mathrm{~m}^{3} / \mathrm{sec}\right)$, and eventually, the experiments were terminated by keeping the same discharge and flow depth until the end.

The hydraulic parameters are shown in Table 1. Sediment was not supplied to the system because the bed in the approach area was almost static, and the ratio of bed shear velocity $u_{*}$ to the threshold shear velocity $u_{*_{c}}$ derived from the Shields diagram for initiation of sediment motion was $u_{*} / u_{*_{c}}=0.87$. The equilibrium time for movable bed experiments was considered as 240 minutes. However in the conventional type, case 0D, the assumed time may not represent the real equilibrium
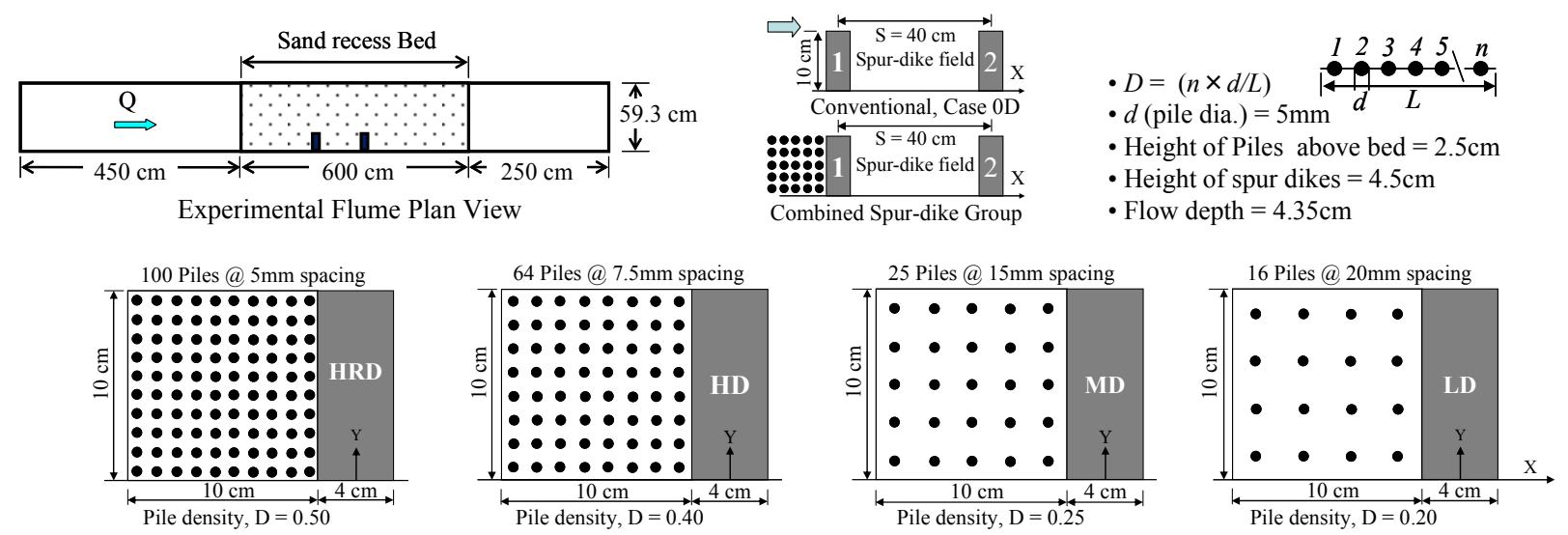

Fig.1 Plan view of experimental flume and physical models 
Table 1 Experimental conditions

\begin{tabular}{|c|c|c|c|c|c|c|c|}
\hline $\begin{array}{c}\text { Discharge } \\
\mathrm{Q}\left(\mathrm{m}^{3} / \mathrm{sec}\right)\end{array}$ & $\begin{array}{c}\text { Flow Depth } \\
\mathrm{h}_{0}(\mathrm{~cm})\end{array}$ & $\begin{array}{c}\text { Channel } \\
\text { Slope }\end{array}$ & $\begin{array}{c}\text { Channel Width } \\
(\mathrm{cm})\end{array}$ & $\begin{array}{c}\text { Approach Flow } \\
\text { Velocity }(\mathrm{cm} / \mathrm{sec})\end{array}$ & $\begin{array}{c}\text { Relative Shear velocity } \\
u_{*} / u_{*_{c}}\end{array}$ & $\begin{array}{c}\text { Reynolds } \\
\text { No. }\left(\mathrm{X} 10^{3}\right)\end{array}$ & $\begin{array}{c}\text { Froude } \\
\text { No. }\end{array}$ \\
\hline \hline 0.0077 & 4.35 & 0.0005 & 60 & 28.40 & 0.87 & 14.28 & 0.45 \\
\hline
\end{tabular}

state due to the existence and continuity of a progressive local scour mechanism. Bed deformation at the end of experiments was measured with a Laser Distance-meter. The velocity was measured by an Electromagnetic Velocimetry in the flat-rough fixed bed with the same flow conditions. 4096 readings were taken from each measurement point with a frequency of $100 \mathrm{~Hz}$ in a plane $1 \mathrm{~cm}$ above the bed. The flat-bed flow is not directly responsible for the scour development, but it is used to show the initiation of bed deformation and compare the models with different arrangements but same bed condition. Concerning the similarity between the flat-bed and deformable-bed vortex structure for pier flows, Dargahi $1990^{15)}$ suggests that such an undertaking is a critical prerequisite before the intricacies of the interaction between the abutment induced vortices and the deformable bed can be explored.

The velocity data is analyzed first to estimate the initiation of bed erosion and directions of topographic changes around the spur dikes, then the bed deformation results are discussed in the following sections.

\section{DATA ANALYSES \& RESULTS}

\section{(1) Flow velocity}

Fig. 2 shows horizontal velocity vectors superimposed on contour of resultant vectors, $U=\sqrt{u^{2}+v^{2}} \cdot u /|u|$, where $u$ and $v$ are the velocity components in $X$ and $Y$ directions, respectively. As it was deemed, the velocity vectors at the upstream of the first spur dike are interspersed due to existence of a pile group. The high value contour in all cases appears in the middle of the flume having an edge close to the tip of first spur dike. This edge is closer to the tip in case $0 \mathrm{D}$, goes farther in the cases with higher pile density (HRD \& HD), and gets closer again in cases with lower pile density (MD \& LD). A flow recirculation zone exists in the spur dike field and plays an important role in sediment transport to the spur dike field. If the velocity of recirculation flow in the spur dike field is too high, deposited sediments leave there by the flow and fall into the deep pool which has been extended from the first spur dike. From there some of them will be transported back to the spur dike field and some others will be transported to the downstream areas, and the persistence of this process belongs to the strength of recirculation flow in the spur dike field.

\section{(2) Bed shear stress}

Reference value of bed shear stress was estimated by using the following equations:

$$
\begin{aligned}
\tau_{b x} & =\rho C_{f} \sqrt{u_{b}^{2}+v_{b}^{2}} \cdot u_{b} \\
\tau_{b y} & =\rho C_{f} \sqrt{u_{b}^{2}+v_{b}^{2}} \cdot v_{b}
\end{aligned}
$$

where $\tau_{b x}$ and $\tau_{b y}$ are longitudinal and transverse bed shear stresses, respectively, $\rho$ is the water density, $C_{f}$ is the bed friction coefficient, $u_{b}$ and $v_{b}$ are the near-bed velocities in streamwise and cross streamwise directions measured at $1 \mathrm{~cm}$ above the bed. These velocity-components, however, do not represent the real near-bed velocities but they are useful as a reference to compare different cases with each other. Because friction coefficient $C_{f}$ is unknown, we normalized these values by the near-bed approach shear stress, $\tau_{b o}$

$$
\tau_{b o}=\rho C_{f} u_{b 0}^{2}
$$

where $u_{b 0}$ is near-bed approach velocity measured $170 \mathrm{~cm}$ upstream from the center of the first spur dike. In this way, the term $\rho C_{f}$ is dropped off from our calculations. Fig. 3 shows the contours of streamwise bed shear stress, $\tau_{b x} / \tau_{b o}$. From these figures the higher values close to the centerline of the flume indicate the erosive potential of the flow in the mainstream area. Furthermore, contours of higher constant values pass closely from tip of the first spur dike in case $0 \mathrm{D}$ and also these lines are close together. This means that the magnitude of the gradient is larger in case $0 \mathrm{D}$ than the other cases. It can also be observed that in the cases with a pile group, the magnitude of the gradient reduces in the cases HRD and HD, but it becomes larger with the decrease of pile density. The maximum local scour depth close to the tip of first spur dike revealed a similar order as the bed shear stress in streamwise direction.

Fig. 4 illustrates contours of the transverse bed shear stress, $\tau_{b y} / \tau_{b o}$. In all cases, contour lines of the higher magnitude coming together close to the neighborhood of the first spur dike, which are higher in case $0 \mathrm{D}$ than the other cases. The values become higher again with the decrease of pile density. In the cases with pile group, the area of 


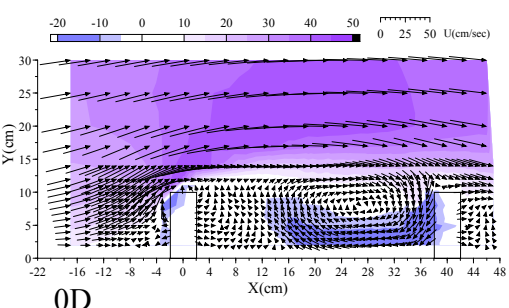

0D
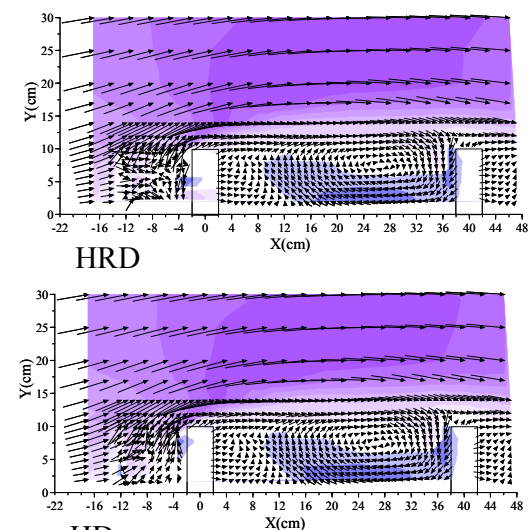

HD

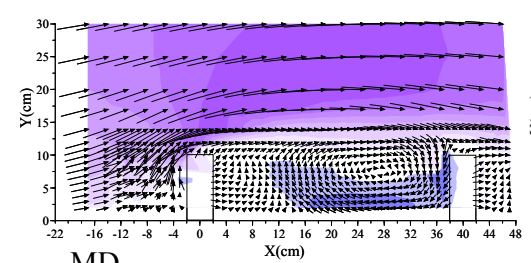

MD

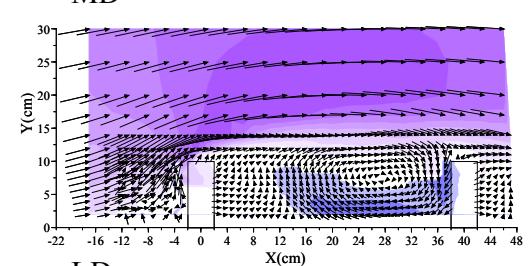

LD

Fig.2 Horizontal velocity vectors \& contours at $Z=1 \mathrm{~cm}$
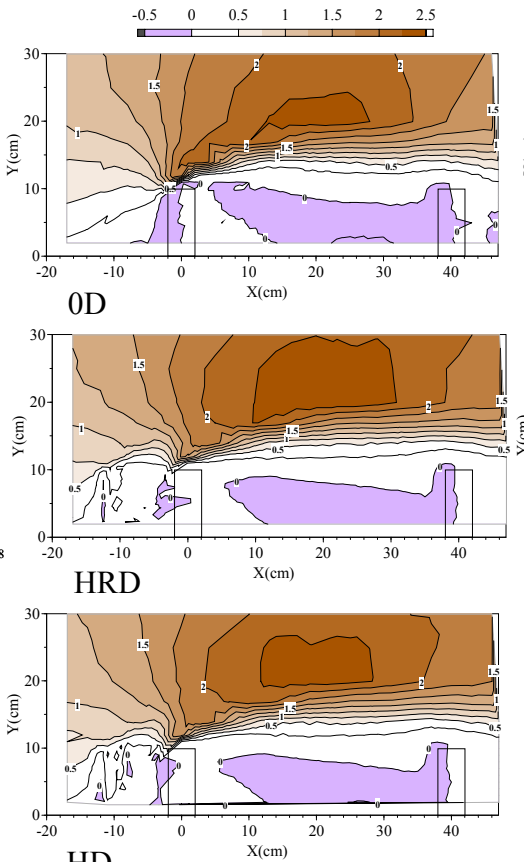

HD
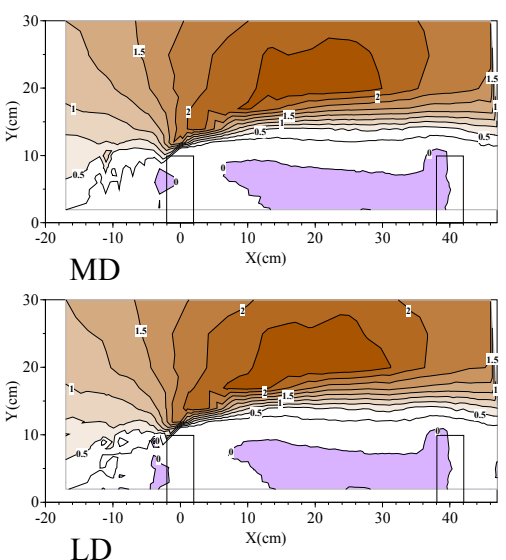

Fig.3 Longitudinal bed shear stress

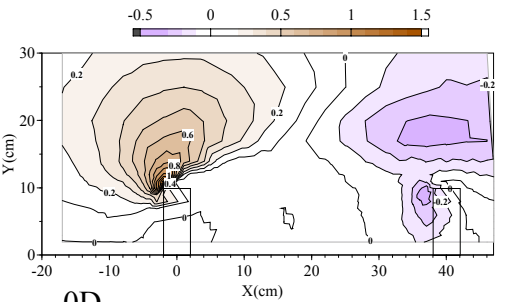

$0 \mathrm{D}$

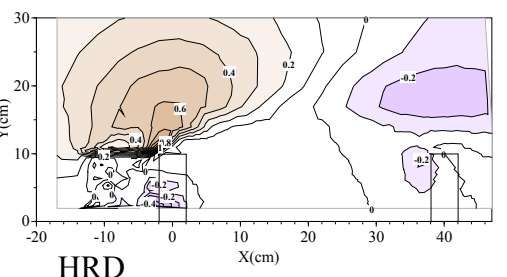

HRD

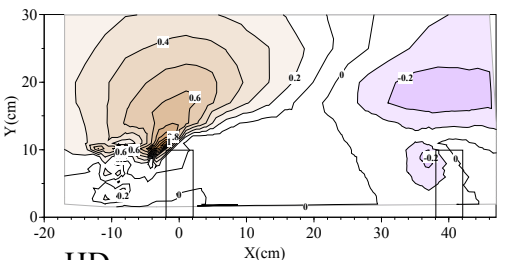

HD
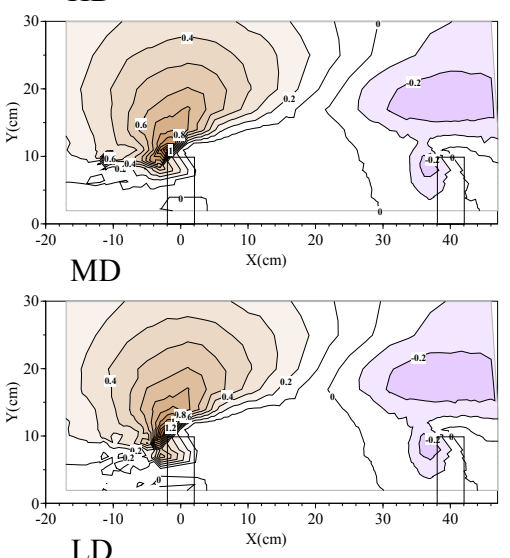

LD

Fig.4 Transverse bed shear stress $\tau_{b y} / \tau_{b o} \geq 0.4$ becomes larger than that in case $0 \mathrm{D}$. Some smaller patches of high values are seen close to the pile groups, but, due to high turbulent flow and instrumentation limits those parts can not be certainly discussed here.

There are negative bed shear stresses of relatively higher values at the vicinity of the tip of second spur dike. It becomes higher especially in case $0 \mathrm{D}$ which suggests a larger amount of erosion at the upstream of the second spur dike. Therefore, a pile group may also reduce local scour at the second spur dike and hence the optimum spacing between spur dikes in a group will also become longer compared with that of conventional spur dikes.

\section{(3) Bed deformation}

The main objectives of installing spur dikes are bank protection by decelerating the velocity and loading fine sediments at the base of the eroding bank and river training for the enough depth in the desired direction.

Bed topographies measured in the selected grids are presented in this section to investigate influence of the modifications on the scouring process and the corresponding flow characteristics. The significant of the spur-dike group performance and the key features like maximum scour depth at the tip of the first spur dike, the deep hole volume, sediment transport and deposition in the spur-dike field and the erosion of bed in front of the spur dikes at the main stream induced by the structural modifications can be extracted from the bed contours depicted in Fig. 5.

Only in case 0D flow causes a progressive local scour around the first spur dike, after about $66 \%$ of the total run time the bottom of the flume was exposed in the upstream side of the model. This limitation surely has some effects on the scour geometry and the deposition area following it. However, in clear water scour, the scour develops 
primarily very rapidly and then approaches equilibrium asymptotically (Chabert and Engeldinger, $1956^{16)}$ ). Therefore, in case 0D after $66 \%$ of run time, the scour will develop very slowly so it may not cause a big deformation.

In this case, a deep scour hole reaches the side bank upstream of the first spur dike. A relatively larger scour hole is also generated at the upstream of the second spur dike as a result of reduction in the length of the return flow zone which in turn causes by the rapid accumulation of the sediments and formation of the high depositional bar in the spur-dike field downstream of the first spur dike. However, if the scour process was reached the real equilibrium stage in this case, the depositional bar would be reduced or disappeared. But still the generation of scour hole at the upstream of the second spur dike is inevitable due to the initial formation of the depositional bar. In case HRD, the higher density of the pile group has changed some essential bed deformation scenarios. As for the scour hole's geometry, bed at the upstream edge of the pile group, tip and downstream of the first spur dike is scoured weakly. Maximum depth of scour is reduced to nearly $50 \%$ of that in case $0 \mathrm{D}$ and located $7.5 \mathrm{~cm}$ downstream from the center of the first spur dike. Amount of deposition in the spur dike field and the height of deposition at the downstream of the second spur dike are reduced in comparison to the case 0D. In the rest of the cases, as the pile density reduces the local scour depth increases accordingly in order, but not as much as in case $0 \mathrm{D}$. As the maximum scour depth in case LD is $20 \%$ less than that in case 0D. Location of the maximum scour depths is at the tip of the first spur dike, similar to the case 0D. Deposition in the spur-dike field and downstream of the second spur dike also increases with the decrease of pile-group density.

\section{DISCUSSIONS}

\section{(1) Flow characteristics}

The resultant flow velocities, $U$, were normalized by approach flow velocity $U_{0}$, to evaluate the velocity profiles in the mainstream close to the tip of spur dikes. Fig. 6 shows the streamwise profiles of the horizontal flow at $Y=11$ $\mathrm{cm}$. The order of peak values at the tip of first spur dike is similar to the order of maximum scour depths, respectively in order, as shown in Fig. 8. In case HRD, the deep scour hole is situated downstream of the first spur dike, also in Fig. 6 in the same location the flow velocity is higher in case HRD than the other cases.
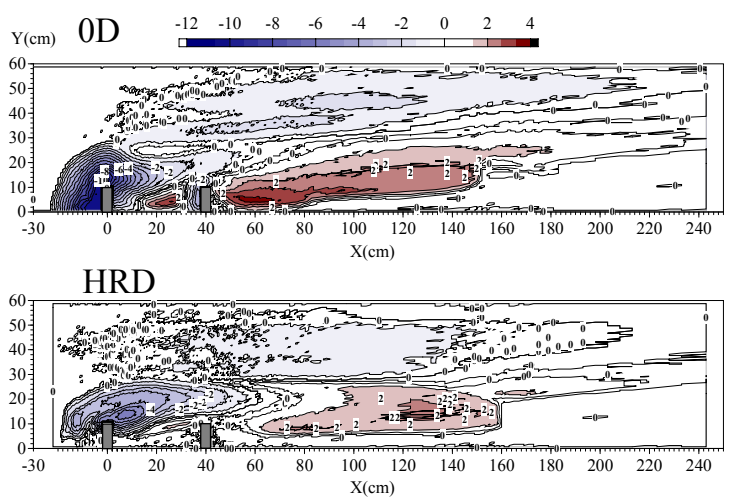

HD
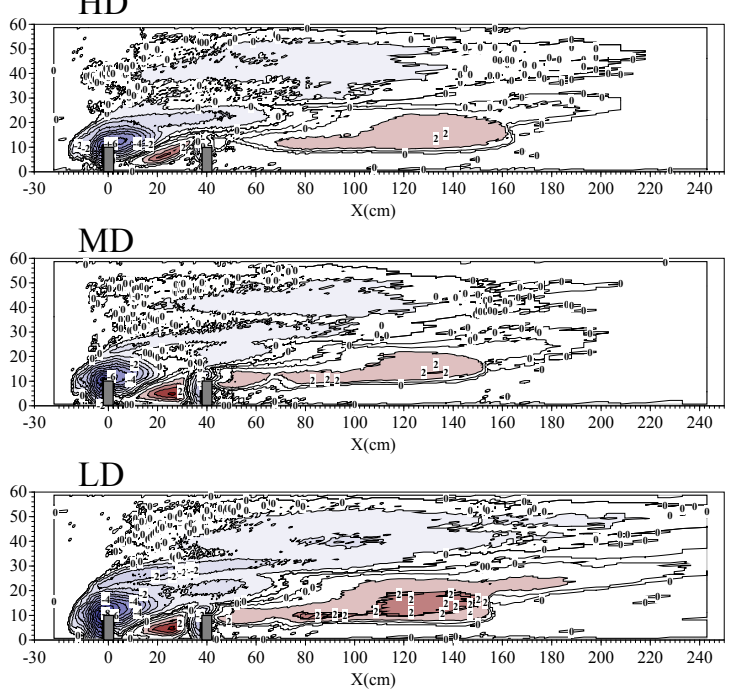

Fig.5 Bed elevation contours

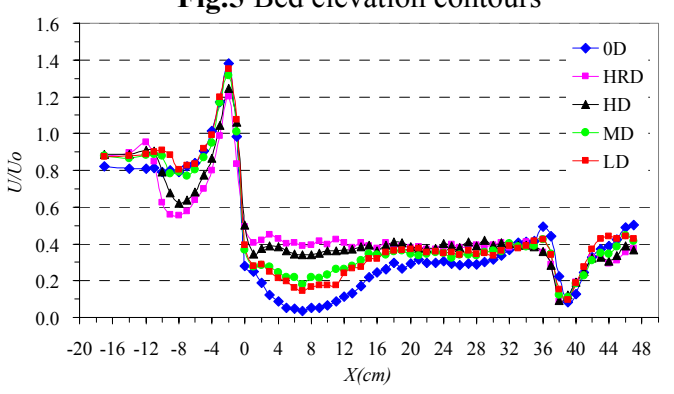

Fig.6 Streamwise profiles of the horizontal flow

Fig.7 illustrates the normalized maximum resultant flow, $U_{\max } / U_{\text {ave }}$, in the spur dike field, where $U_{\text {ave }}$ is the averaged resultant flow in the spur dike field. The maximum value belongs to the case $0 \mathrm{D}$, and decreases with the increase of pile density. Erosion volume in the spur dike field (Fig. 8) also shows a similar trend.

\section{(2) Bed form characteristics}

The scouring volume, $v_{s c}$, of deep pool (the so called en bloc scour hole $0.9 \mathrm{~cm}$ beneath the zero bed level) was calculated based on the method of totaling prismatic volumes with triangular roofs, from the upstream to the downstream area around the spur-dike group excluding any other minor and separated erosion patch near the opposite bank or in the far downstream. The scour volume then was 
normalized by $a_{s c} \times h_{0}$, where $a_{s c}$ is the mean of scouring planform area of all cases, and $h_{o}$ is the approach flow depth. In the same way, volume of deposition, $v_{d}$, in the spur-dike field above the zero bed was calculated and normalized by $a_{d} \times h_{0}$, where $a_{d}$ is the mean of deposition area of all cases. Volume of erosion, $v_{e}$, in the spur-dike field was also calculated and normalized by $a_{e} \times h_{0}$, where $a_{e}$ is the mean erosion area of all cases. Fig. 8 shows the bed form characteristics variations with its tabular data for all cases.

Case 0D has the highest maximum scour depth $d_{s m}$, the highest volumes of scouring $v_{s c}$, and erosion $v_{e}$. In the cases with a pile group, maximum scour depth increases with the decrease of the pile-group density, but volume of scouring reduces except in the case of low pile density (LD). This behavior indicates the shrinkage of the scour hole planform area, except case LD with a low pile-group density that becomes more similar to the case 0D in some of its characteristics. Volume of deposition in the spur-dike field is the smallest in the case HRD and increases with the decrease in the pile-group density, again case LD is an exception. A relative balance between erosion and deposition in the spur-dike field exists in cases HD and MD.

\section{CONCLUSIONS}

Local scouring is a major concern to the efficient performance of a spur dike. Installation of a pile group at the upstream adjacent of the spur dike can reduce the local scour and volume of scouring. Erosion of the bed in the spur-dike field can be reduced and deposition in the spur-dike field can be promoted by altering the density of the pile group. Estimation of these features and selection of a suitable density for the pile groups becomes very handy to restore a river reach as per demands.

The turbulence of flow around the submerged pile-group makes it difficult to measure the flow field around the piles in detail. And also intrusion of a measurement sensor into a pile group spaced close together causes some uncertainties in measurement due to the flow compression effects. Therefore some other methods such as PIV are required to measure detailed flow structure inside the pile group.

\section{REFERENCES}

1) Darrow, J. D.: Effects of bendway weir characteristics on resulting flow conditions, M.S. Thesis. Colorado State Univ., Dept. of Civil Eng., Fort Collins Co., 2004.

2) Zhang, H.: Study on flow and bed deformation in channels with spur dikes, Doctoral Dissertation, Kyoto Univ, 2005.

3) Kuhnle, R. A., Alonso, C. V. and Shields, F. D., Local scour associated with angled spur dike, Journal of Hydraulic Eng., ASCE, 128(12), pp.1087-1093, 2002.

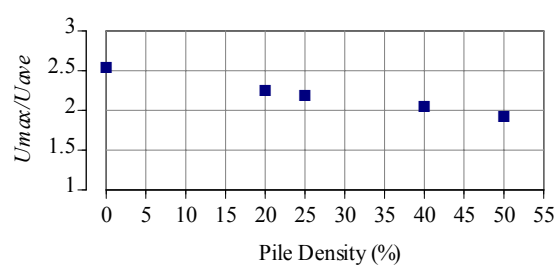

Fig.7 Normalized maximum resultant velocity

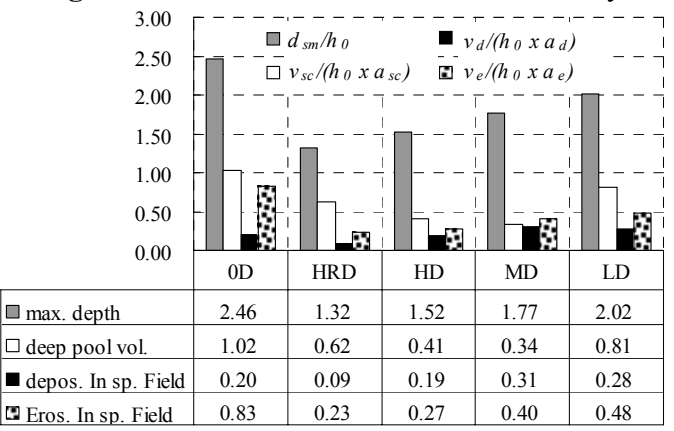

Fig.8 Bed deformation characteristics

4) Biron, P. M., Robson, C., Lapointe, M. F. and Gaskin, S. J.: Three-dimensional flow dynamics around deflectors, River Research and Application, 21(9), pp.961-975, 2005.

5) Tominaga, A. and Matsumoto, D.: Diverse riverbed figuration by using skew spur-dike groups, River Flow 2006, 1, Balkema, pp.683-691, 2006.

6) Haltigin, T. W., Biron, P. M. and Lapointe, M. F.: Predicting equilibrium scour hole geometry near angled stream deflectors using a three-dimensional numerical flow model, Journal of Hydraulic Eng., 133(8), pp.983-988, 2007.

7) Garde, R. J., Subramanya, K. and Nambudripad, K. D.: Study of scour around spur dikes, Journal of Hydraulic Div. Am. Soc. Civ. Eng., 87(6), pp.23-38, 1961.

8) Gill, M. A.: Erosion of sand beds around spur dikes, Journal of Hydraulic Div. Am. Soc. Civ. Eng., 98(9), pp.1587-1602, 1972.

9) Klaasen, G. J., Douben, K. and Van er Waal, M.: Novel approaches in river engineering, River flow 2002, Bousmar and Zech, eds., Swets and Zeitlinger, Lissed, pp.27-42, 2002.

10) Mioduszewski, T., Maeno, S. and Uema, Y.: Influence of the spur dike permeability on flow and scouring during a surge pass, International Conf. on Estuaries and Coasts, Hangshou, China, pp.380-388, 2003.

11) Zhang, H. and Nakagawa, H.: Scour around spur dike: Recent advances and future researches, Annuals of Disas. Prev. Inst., Kyoto Univ., No51B, 20p., 2008.

12) Baba, Y., Camenen, B., Peltier, Y., Thollet F. and Zhang, H.: Flows and bedload dynamics around spur dike in a compound channel, $11^{\text {th }}$ International Symposium on River Sedimentation, pp.6-9, 2010.

13) Alauddin, M., Tashiro, T. and Tsujimoto, T.: Design of groynes modified with both alignment and permeability for lowland river problems, Journal of Applied Mechanics, JSCE, 2(67), pp.645-652, 2011.

14) Sadat, S. H., Tominaga, A. and Cai, F.: Protective pile group for scour mitigation of existing spur dike group, Proceedings of 2013 IAHR World Congress, 2013.

15) Dargahi, B.: Controlling mechanism of local scouring, Journal of Hydraulic Eng., ASCE, 116(10), pp.1197-1214, 1990.

16) Chabert, J. and Engeldinger, P.: Etude des afouillements autour des piles des ponts, Laboratoire National d'Hydraulique, Chatou, France (in French), 1990.

(Received September 30, 2013) 